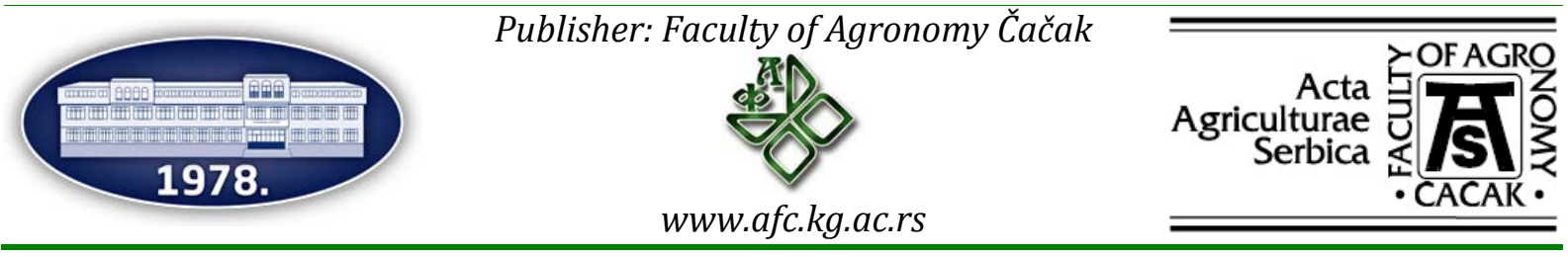

\title{
Scientific and pedagogical life an outstanding Russian microbiologist of the 20th century
}

\author{
Aleksandar Mihailovič Semenov ${ }^{*}$, Dragutin A. Đukić \\ ${ }^{1}$ Faculty of Biology, Lomonosov Moscow State University, Leninskie Gory 1-12, 119234 Moscow, Russia \\ ${ }^{2}$ Faculty of Agronomy, University of Kragujevac, Cara Dušana 34, 32000 Čačak, Serbia \\ *Corresponding author: amsemenov@list.ru
}

Evgeny Nikolaevich Mishustin - as his daughter Irina Mishustina wrote - died on Friday, May 3, 1991, three hours before sunrise, at the age of 90 .

An outstanding person, scientist, professor and teacher have died, but the memory of him and his grand work will remain forever. This 22 February 2021 will mark 120 years since his birth and 30 years since his death.

As a student at the Petrovskaya Agricultural and Forestry Academy, later named K.A. Timiryazev, now the Russian State Agrarian University - Moscow Agricultural Academy named after K.A. Timiryazev, E. Mishustin got the opportunity to adopt the knowledge of outstanding Russian scientists in various fields of agriculture, such as D.A. Sabinin, D.A. Pryanishnikov, R.V. Williams, N.N. Khudyakov and other scientists of the early 20th century. His diploma work, performed under the direction of N.N. Khudyakov at the Timiryazev Academy, determined all his further direction in the life and success in science.

In fact, E.N. Mishustin was the founder of soil microbiology in the former USSR and the Warsaw Pact countries (socialist countries), although for historical and scientific clarity it should be noted that after the opening of the Institute of Microbiology in Moscow (1934) N.A. Krasilnikov was formally the head of the laboratory of soil microbiology.

It should be noted that teaching and research in microbiology, in that time of the formation of Evgeny Nikolaevich, as a future world scientist, of course, was and actively developed, but the development was general, that is, the development of general microbiology.

Although, as Evgeny Nikolayevich describes in a book written by himself during his lifetime (Mishustin E.N. My life in science. Memoirs. M. Science. 1997. 272 p. in Russ.), in the 20s - 40s years of the last century, the USSR already formed such particular areas of microbiology as agricultural microbiology, milk microbiology and others. However, exactly E.N. Mishustin from Agrochemical Institute (VIUAA) was invited to the Institute of Microbiology of the USSR Academy of Sciences by academician B.L. Isachenko towards the development of soil microbiology, and it was successfully done.

Mishustin E.N. took part in setting up and organising research in a large number of other institutions and scientific structures, such as the Institute of Soil, Institute of Fodder Crops, Institute of Animal Husbandry, Institute of Cereal Crops, Sanitary Institute, Institute of Municipal Hygiene, Institute of Canning Industry, Agricultural Academy, etc.

Mishustin E.N. began his teaching career as a teacher in a secondary school in Moscow, and then was elected assistant professor of the Department of Technological Microbiology of the Moscow Mendeleev Institute and in the subject "Milk Microbiology" at the Moscow Agricultural Academy named after K.A. Timiryazev. Taught a course in soil microbiology at Moscow State University named after M.V. Lomonosov and was a professor of the Department of Biochemistry and Microbiology of the Food Academy named after V.I. Stalin. The most significant was his head of the Department of Microbiology of the Moscow Agricultural Academy. K.A. Timiryazev.

Mishustin E.N. supervised more than 80 candidate and 15 doctoral theses and had producing scientists from almost all former USSR countries, but also by those from Bulgaria, Hungary and Czechoslovakia.

Mishustin E.N. was head editor or an editorial board member of numerous journals (Izvestiya Akademii Nauk SSSR. Seriya Biologicheskaya; Mikrobiologiya; Selskokhozyaistvennaya Biologiya. [In Russ.]), and an editor and reviewer of a large number of monographs, textbooks, exercise books, handbooks and collections of papers.

Memories of Academician E. N. Mishustin would be incomplete without giving due attention to his main research orientations, which significantly improved agricultural production and contributed to the success of Russia in the $21^{\text {st }}$ century in terms of the production of sufficient amounts of food for both its own needs and export.

Academician Mishustin's main research interests and contributions included the following: 
1 - Study the cultivated microbial community composition of different soil types, which was associated with the ecological variability of microorganisms. In this way he further developed S.N. Vinogradsky's notion of indigenous (autochthonous) and zymogenous microbial communities of different soil types, and thus elaborated on the concept of soil microbial cenoses and their ecological and geographic variability, which laid the foundation for the science of soil (terrestrial) microbial ecology. This theoretical framework led to practical recommendations regarding soil cultivation methods in different regions, soil type and fertility diagnosis, and soil hygienic status. These studies resulted in the publication of important monographs, including ecological and geographic variability of soil bacteria, thermophilic microorganisms in nature and practice microorganisms and soil self-purification, the microflora of soils in northern and central regions of the USSR, the microflora of soils in the southern region of the USSR, soil microbial associations.

2 - Study of nitrogen fixation by microorganisms of atmospheric nitrogen and use of biological nitrogen in agriculture. Mishustin E.N. and his numerous collaborators in the first and early second half of the 20th century created a collection of active cultures (nodule) symbiotic and nonsymbiotic (freeliving) bacteria for the main cultures of legumes and non-legumes grown on various soils in the USSR. In this area, Mishustin published monographs on biological fixation of atmospheric nitrogen, nodule bacteria and inoculations, soil nitrogen-fixing microorganisms of the genus Clostridium, and also edited collections of articles biological nitrogen and its role in crop production, novelties in the study of biological fixation of atmospheric nitrogen, circulation and balance of nitrogen in the system, soil - fertilizers - plants, mineral and biological nitrogen in soil cultivation in the USSR and biological nitrogen in agriculture in the USSR. Meanwhile, modern studies have shown that in healthy fallow soil, nitrogen-fixing activity, both actual and potential, turns out to be in the borderline region of sensitivity of the methods used for quantitative determination of nitrogen fixation. This indicates that the practical contribution of the nitrogen fixation process in providing nitrogen to the native (healthy) soil ecosystem is ephemeral. At the same time, the practitioners of modern organic farming introduced the use of legumes (i.e., symbiotic nitrogen fixation) to replenish nitrogen in the soil ecosystem in the international guidelines on organic technologies in the form of obligatory requirements, which was promoted by E.N. Mishustin.
3 - Soil structure and microbiology of soil fertility preservation, the fate of humus as the main "holder" of the organo-mineral matter of the soil, were Mishustin's major lifelong preoccupations. Now this concept has evolved into the soil health i.e. soil ecosystem health concept, which includes physicochemical properties of the soil and its biological diversity in terms of the soil microbiome and maintenance of productivity as the ability to provide biophilic elements to the soil ecosystem. Mishustin E.N. focused particularly on pedogenesis and pedoaccumulation and the role of microorganisms in these processes.

4 - Role of soil cultivation on microbiological processes in the soil, which is dealt with in great detail in the collection of papers The Cultivation of Soil and Its Effective Fertility, edited by E.N. Mishustin.

5 - Use of straw as an organic fertiliser for soils. Straw as annual crop residue may be a good organic fertiliser, but only on correct applied by nitrogen in such soil system and the management nitrogen-fixing bacteria. The results of this research were published in the collections of papers Increasing the Fertility of Rice Soils, Use of Straw as an Organic Fertiliser, Increasing the Productivity of Rice Soils.

6 - Partial sterilisation of agricultural soils with substances used for military purposes (chlorine, chloroacetone, chloropicrin etc.), particularly soils in closed spaces. Fragments of the research results were reported in several articles published in the journal "Himizacija sel'skogo hozjajstva (in Russ.)".

7 - Elaboration of microbiological indicators of the quality of cereals and their toxic properties.

8 - Rational ensiling and haying methods.

Mishustin E.N. published his own results and his students' and colleagues' findings in a large number of books (monographs, textbooks, books of exercises, handbooks) and over 640 research articles and technical papers. He wrote forewords or prefaces, and was an editor and reviewer for a variety of publications.

In his scientific career, E.N. Mishustin visited a great number of scientific institutions and was directly engaged in numerous congresses, symposia, conferences and other events in the USSR and abroad (Poland, Italy, Czechoslovakia, Germany, France, China, the USA, Belgium, Romania, Great Britain, Canada, Sweden, Hungary, Ethiopia, Japan, India, Mexico, Australia, Bulgaria, Yugoslavia, Spain, New Zealand, Greece, Austria, the Netherlands, Finland).

Mishustin E.N. received numerous state-level, professional and other awards for his exceptional results in the fields of agricultural sciences and higher education in the country and abroad. 